\title{
Advagraf vs. Prograf Immunosuppressive Therapy in De Novo Kidney Transplant: A Single Center Experience
}

La Manna G*, Todeschini P, Capelli I, Cappuccilli M, Cuna V, Battaglino G, Patregnani L, Liviano D'Arcangelo G and Scolari MP

Department of Experimental, Diagnostic and Specialty Medicine, S. Orsola University Hospital, Italy

*Corresponding author: Gaetano La Manna, Department of Experimental, Diagnostic and Specialty Medicine, Dialysis, Nephrology and Transplantation Unit, S. Orsola University Hospital, via Massarenti 9, 40138 Bologna, Italy, Tel: ++39 (051) 6364577; Fax: ++39(051)344439; E-mail: gaetano.lamanna@unibo.it

Rec date: Mar 25, 2014, Acc date: Apr 22, 2014, Pub date: Apr 24, 2014

Copyright: ( 2014 La Manna G, et al. This is an open-access article distributed under the terms of the Creative Commons Attribution License, which permits unrestricted use, distribution, and reproduction in any medium, provided the original author and source are credited.

\begin{abstract}
Background: Short-term results of renal transplantation have shown a drastic improvement over time mainly due to changes in immunosuppressive therapy. Non-compliance to therapy is one of the causes of graft loss. Tacrolimus is a cornerstone of immunosuppressive therapy: recently became available Tacrolimus once a day formulation (Advagraf) that could improve the compliance of patients to immunosuppressive therapy. Few are published data about its use in clinical practice. We therefore compared the efficacy and pharmacokinetics of once-daily formulation compared to the classic twice-daily dosing tacrolimus in de novo kidney transplant patients.
\end{abstract}

Methods: Retrospectively evaluation of 30 de novo transplant recipients treated with Advagraf in 2009-2012 (on dose daily of $0.2-0.3 \mathrm{mg} / \mathrm{kg}$ ) and 30 treated with Prograf ( 2 doses daily of $0.2 \mathrm{mg} / \mathrm{kg}$ ). Comparison between the two groups regarding drugs dose, blood level and clinical variables.

Result: Both Advagraf and Prograf patients reached the drug target level, even if initially with a higher drug dose for Advagraf. Creatinine levels were initially higher in Advagraf group, no differences are detectable two weeks after transplant. There were no differences between groups for rejection episodes, graft loss and adverse events. Lipid metabolism was significantly better in Advagraf patients.

Discussion: Advagraf confirm to offer a similar short-term efficacy compared with the twice a day administration in de novo kidney transplant, with a higher drug dose compared to tacrolimus. The safety profile is comparable with twice-daily administration. Interestingly a better lipid metabolism is present in Advagraf group.

Keywords: Kidney transplant; Immunosuppression; Tacrolimus; Once-daily; Twice-daily

\section{Introduction}

Graft rejection is the most important challenge for the clinician involved in the field of transplantation compared. The development of new immunosuppressive agents and new formulations is turned to the optimization of immunosuppressive therapy, offering a variety of possible treatment regimens.

Tacrolimus is definitely a landmark in the field of immunosuppressive therapy as confirmed by the results of numerous studies that have shown a significant reduction in the incidence and severity of episodes of acute rejection in kidney transplant recipients treated with this drug - in combination with mycophenolate mofetil, steroids and basiliximab - with improved graft survival in the long term. The formulation of tacrolimus (Prograf) requires two daily dosing. It was developed in a sustained release oral formulation, FK506E (ADVAGRAF), to allow for once-daily administration of tacrolimus, while maintaining a safety and efficacy profile similar to that of Prograf.

It has been shown that poor compliance is one of the factors associated with graft loss [1,2]: therefore, the conditions that improve adherence to immunosuppressive therapy can impact significantly on graft survival in the long term. In this context, the once-daily therapy carries the potential advantage [3] to improve patient compliance.

To date, however, there are few published data concerning its use in clinical practice, especially as the initial immunosuppressive therapy in the new transplants [4-7]. We therefore compared the efficacy and pharmacokinetics of single-dose formulation compared to the classic twice-daily dosing tacrolimus in de novo kidney transplant patients.

\section{Methods}

We retrospectively evaluated 30 de novo transplant recipients treated with Advagraf in 2009-2012 (dose of $0.2 \mathrm{mg} / \mathrm{kg} /$ day). These patients were compared with the Prograf group (30 de novo patients transplanted between 2009-2012 always treated with tacrolimus in 2 doses daily (Prograf $0.2 \mathrm{mg} / \mathrm{kg} /$ day). The target levels in patients treated with tacrolimus once a day were as follows : 10 to $15 \mathrm{ng} / \mathrm{ml}$ in the first 2 weeks, $7-12 \mathrm{ng} / \mathrm{mL}$ from day 14 to day $28,5-10 \mathrm{ng} / \mathrm{mL}$ from day 29 to day 56 and 5-7 ng/ml from day 57 onwards. The target levels in patients treated with tacrolimus twice a day were $10-12 \mathrm{ng} / \mathrm{ml}$ in the first 2 weeks, $6-10 \mathrm{ng} / \mathrm{mL}$ from day 14 to day $28,5-10 \mathrm{ng} / \mathrm{mL}$ from day 29 onwards.

In both groups induction therapy was made with monoclonal antiCD25 antibody (2 doses). The maintenance therapy with tacrolimus was associated with mycophenolate mofetil/mycophenolic acid and 
Citation: La Manna G, Todeschini P, Capelli I, Cappuccilli M, Cuna V, et al. (2014) Advagraf vs. Prograf Immunosuppressive Therapy in De Novo Kidney Transplant: A Single Center Experience. J Transplant Technol Res 4: 129. doi:10.4172/2161-0991.1000129

Page 2 of 5

steroid. All patients were treated with sulfamethoxazole-trimethoprim as prophylaxis.

We excluded patients treated with Thymoglobuline, patients participating in study protocols, patients receiving an $\mathrm{ABO}$ incompatible transplantation and patients with follow-up less than 3 months at the time of the study.

For each patient, we collected from patients medical records the following data: age and sex of the donor, the recipient's age, gender and race, number of prior transplant, peak panel reactive antibodies (PRA) before transplantation, pre-transplant history of diabetes (defined according to the criteria of American Diabetes Association), creatinine measurements on postoperative days $1^{\circ}-15^{\circ}-30^{\circ}-60^{\circ}-90^{\circ}-180^{\circ}$ and at discharge in both groups, the blood level of tacrolimus and the respective drug dose at the 7 th $-15^{\circ}-30^{\circ} 60$ - $90^{\circ} 180^{\circ}$ post-operative day in both groups. We also collect data about lipid profile (cholesterol, triglycerides, HDL, LDL), number of acute rejection, adverse events (neurological disorders, development of post-transplant diabetes, infections and hypertension) and graft loss.

\section{Statistical Analysis}

The values of the variables taken into account in this study are expressed as mean \pm SD for both groups. Comparisons between study groups were performed using $\mathrm{t}$-tests or $\chi^{2}$ tests when appropriate. Values of $\mathrm{P}<0.05$ were considered statistically significant.

\section{Results}

There were no statistically significant differences between the two groups in terms of patient characteristics. Creatinine levels were significantly higer in advagraf group only in the first two weeks after transplant. However the tacrolimus blood levels were initially higher in the group treated with Advagraf which required the use of higher doses mainly in the first weeks post-transplant. Then in both group tacrolimus blood level is similar and appears stable but the drug dose is higher in advagraf group (Figure 1).

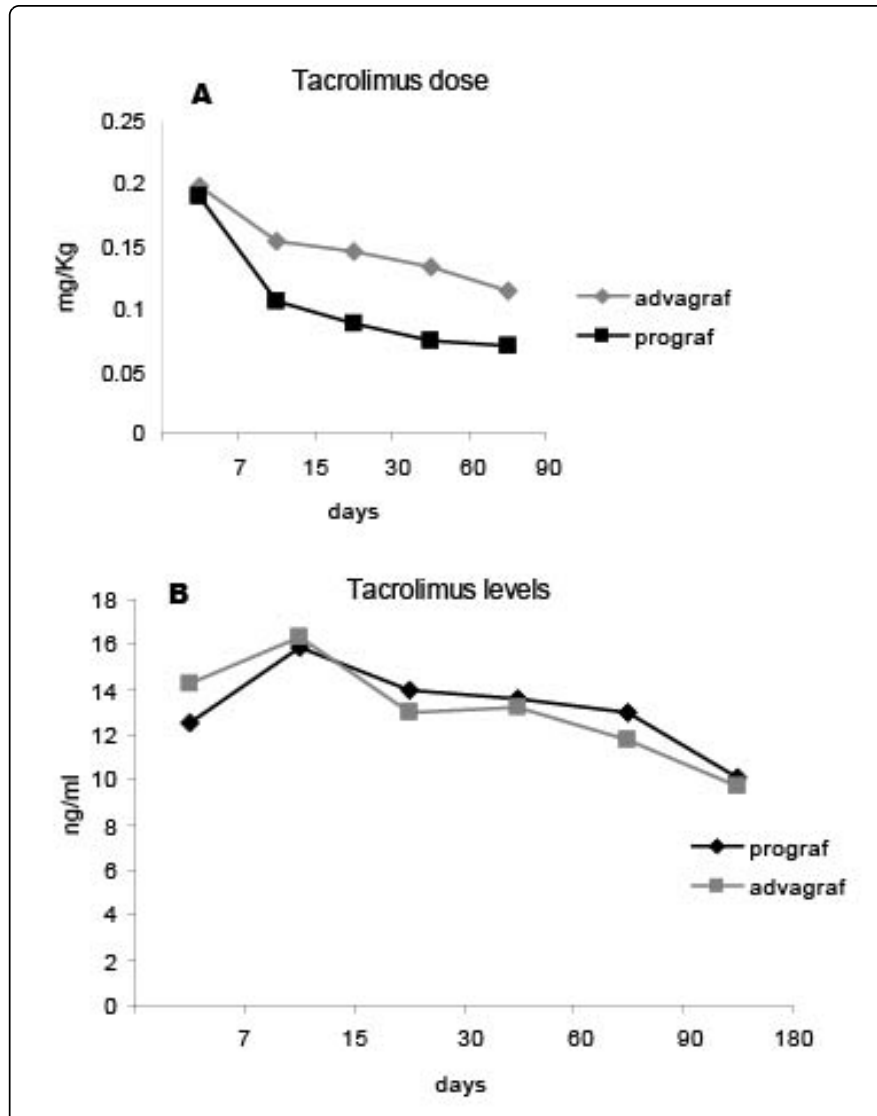

Figure 1: Tacrolimus dose (A) and blood levels (B) in Advagraf and Prograf group of patients. There were no significant differences in tacrolimus levels. In patients treated with Advagraf dosage used was higher.

The incidence of rejection was similar (1 steroid-sensitive acute rejection in both groups). No graft loss was reported in both groups, also due to the short follow-up (Table 1).

\begin{tabular}{|l|l|l|l|}
\hline \multirow{2}{*}{ Variable } & Advagraf group & Prograf group & p-value \\
\cline { 2 - 4 } & $(\mathrm{n}=30)$ & $(\mathrm{n}=30)$ & \\
\hline Donor & & & $\mathrm{ns}$ \\
\hline age (years) & $58 \pm 12$ & $55 \pm 12$ & $\mathrm{~ns}$ \\
\hline gender (male /female) $\mathrm{n}(\%)$ & $19 / 11(63.3 / 37.7) 4 / 26(13.3 / 86.7)$ & $18 / 12(60 / 40)$ & $\mathrm{ns}$ \\
\hline donor type (living/decesed) $\mathrm{n}(\%)$ & & $10 / 20(33.3 / 66.7)$ & $\mathrm{ns}$ \\
\hline Recipient & & & $\mathrm{ns}$ \\
\hline age (years) & $53 \pm 11$ & $47 \pm 13$ & $\mathrm{~ns}$ \\
\hline gender (male /female) (n) & $17 / 13(56.7 / 43.3)$ & $20 / 10(66.7 / 33.3)$ & $\mathrm{ns}$ \\
\hline Second transplant & $2(6.7)$ & $2(6.7)$ & $\mathrm{ns}$ \\
\hline Peak PRA (\%) & $2.8 \pm 3.1$ & $2.6 \pm 3.3$ & $3(10)$ \\
\hline Pre Tx diabetes, $\mathrm{n}(\%)$ & $3(10)$ & & \\
\hline
\end{tabular}


Citation: La Manna G, Todeschini P, Capelli I, Cappuccilli M, Cuna V, et al. (2014) Advagraf vs. Prograf Immunosuppressive Therapy in De Novo Kidney Transplant: A Single Center Experience. J Transplant Technol Res 4: 129. doi:10.4172/2161-0991.1000129

Page 3 of 5

\begin{tabular}{|c|c|c|c|}
\hline Acute rejection, $\mathrm{n}(\%)$ & $1(3.3)$ & $1(3.3)$ & ns \\
\hline Graft loss, n (\%) & 0 & 0 & ns \\
\hline \multicolumn{4}{|c|}{ Creatinine levels (mg/dl) } \\
\hline day 7 & $4.1 \pm 0.2$ & $3.9 \pm 0.2$ & $<0.001$ \\
\hline day 15 & $3.1 \pm 0.2$ & $2.5 \pm 0.1$ & $<0.001$ \\
\hline day 30 & $1.9 \pm 0.2$ & $1.8 \pm 0.2$ & ns \\
\hline day 60 & $1.6 \pm 0.2$ & $1.7 \pm 0.2$ & ns \\
\hline day 90 & $1.6 \pm 0.2$ & $1.6 \pm 0.2$ & ns \\
\hline day 180 & $1.5 \pm 0.2$ & $1.4 \pm 0.2$ & ns \\
\hline \multicolumn{4}{|l|}{ Lipid levels: } \\
\hline \multicolumn{4}{|l|}{ Total cholesterol (mg/dl) } \\
\hline day 30 & $216.8 \pm 28.1$ & $245.0 \pm 30.2$ & $<0.001$ \\
\hline day 60 & $211.2 \pm 23.7$ & $239.3 \pm 34.1$ & $<0.001$ \\
\hline day 90 & $209.7 \pm 19.7$ & $237.8 \pm 34.2$ & $<0.001$ \\
\hline \multicolumn{4}{|l|}{ Triglycerides (mg/dl) } \\
\hline day 30 & $190.8 \pm 45.8$ & $226.0 \pm 42.3$ & $<0.001$ \\
\hline day 60 & $180.6 \pm 41.0$ & $214.1 \pm 46.8$ & $<0.001$ \\
\hline day 90 & $188.2 \pm 40.6$ & $222.1 \pm 40.6$ & $<0.001$ \\
\hline \multicolumn{4}{|c|}{ HDL Cholesterol (mg/dl) } \\
\hline day 30 & $88.6 \pm 3.9$ & $66.9 \pm 14.1$ & $<0.001$ \\
\hline day 60 & $88.9 \pm 3.9$ & $69.8 \pm 14.9$ & 0.001 \\
\hline day 90 & $89.5 \pm 3.6$ & $66.2 \pm 15.2$ & $<0.001$ \\
\hline
\end{tabular}

Table 1: Characteristics of donors and patients and graft outcomes.

2 patients (6.7\%) treated with advagraf and 3 patients $(10 \%)$ treated with prograf presented delay graft function (DGF) $(\mathrm{p}=0.64) .2$ patients per group were treated with ganciclovir as prophylaxis for CMV infection.From the point of view of drugs safety, no differences were found in the side effects presentation: patients experienced neurological disorders (headache, tremors) in similar proportion $(30 \%$ of patients treated with Advagraf vs. $27 \%$ in patients treated with
Prograf). In both groups the onset of diabetes after transplantation was reported (according to the ADA criteria), with similar proportion (10\% vs. $12 \%)$. The prevalence was comparable also for systemic infections (CMV, Polyoma virus). Hypertension has been exacerbated in patients with a history of hypertension in both groups (Advagraf $5 \%$ vs. Prograf 5\%), while there has been no outbreak of a newly detected hypertension in patients with no history of hypertension (Table 2).

\begin{tabular}{|l|l|l|l|}
\hline \multirow{2}{*}{ Variable } & Advagraf group & Prograf group & \multirow{2}{*}{-value } \\
\cline { 2 - 4 } & $(\mathrm{n}=30)$ & $(\mathrm{n}=30)$ & \\
\hline $\begin{array}{l}\text { Neurologic disorders (tremors, } \\
\text { headheache) }\end{array}$ & $4(13)$ & $5(16)$ & $\mathrm{ns}$ \\
\hline Post transplant diabetes & $3(10)$ & $4(13)$ & $\mathrm{ns}$ \\
\hline Hypertension & $8(26)$ & $9(30)$ & $\mathrm{ns}$ \\
\hline Infections (CMV, BKV) & $3(10)$ & $2(6)$ & $\mathrm{ns}$ \\
\hline
\end{tabular}

Table 2: Adverse events. 
Regarding laboratory tests, we evaluated the mean values of cholesterol, HDL and triglycerides showing lower levels of total cholesterol and triglycerides and higher HDL cholesterol levels in the group of patients treated with tacrolimus once-daily.

\section{Discussion}

The results of this study seem to confirm that the one dose of tacrolimus formulation offers a similar short-term efficacy compared with the twice a day administration in de novo kidney transplant in association with steroids, mycophenolate mofetil and anti CD 25 antibody [8-11]. No differences were identified in the two groups for each determination of creatinine levels after the first two weeks after transplant. We can assume that the higher initial levels correspond to the initial need to use higher doses of the drug in the group treated with Advagraf and to the initial, also not significant, higher drug level that may slightly delay the functional recovery of the graft. However, there were not significant differences between the two groups in terms of delayed graft function, intended as the need for dialysis in the first week after transplantation not motivated by hyperkalemia. The impact on the long-term effect of the drug on functional recovery cannot be deduced from our data, but should be noted that already after two weeks the values of renal function did not differ significantly between the two groups and that this is true for all subsequent observation period. The data show, however, the need to use an higher drug dose for Advagraf group to achieve therapeutic levels (11-15 $\mathrm{ng} / \mathrm{ml})$. This is confirmed by the data of the literature and is linked to the once-daily administration that inevitably leads to a lower baseline value when compared with twice-daily dosing regimen [12-14].

Both immunosuppressive formulations confirm the safety profile as well as for side effects. Evaluating the adverse events that may be relative to immunosuppressive therapy as the appearance of neurological disorders, hypertension, diabetes and $\mathrm{cmv}$ and polyoma virus post-transplant infections, these were comparable in the two groups. This result agree with published data [15].

Notoriously lipid metabolism may be altered in patients who are receiving immunosuppressive therapy [16]. CNI are among the immunosuppressive drugs that can cause this type of metabolic disorder. Some studies in literature show a lower incidence of hypercholesterolemia in tacrolimus treated patients compared with cyclosporine [17]. While for cyclosporine the correlation between lipid blood level and the drug blood level appears demonstrated, there are uncertain correlations between the tacrolimus blood levels and lipid metabolism. Other study that investigated the conversion from once daily to twice daily tacrolimus formulations didn't sowed a difference did not show a significant difference in terms of lipid profile after transplantation between the two regimens $[18,19]$. Otherwise showed a lower impact of once-daily formulation on carbohydrate metabolism [19]. In our study interestingly there are the lower levels of total cholesterol and triglycerides and the higher levels of HDL cholesterol in advagraf group. Although the pathogenic mechanism that may explain this finding remains to be clarified, also in this case the result does not seem to be in this case related to the drug blood level which as above mentioned are initially higher for once daily administration, although not significantly. This finding, that deserves further study and needs confirmation in randomized controlled trials that evaluate also the basal cholesterol, could be of crucial importance in the context of patients who have a notoriously high cardiovascular risk profile [20]. We therefore believe that Advagraf represents a valid therapeutic regimen in immunosuppressive therapy for kidney transplantation in combination with steroids, mycophenolate mofetil and anti-CD 25 monoclonal antibodies.

\section{References}

1. Schweizer RT, Rovelli M, Palmeri D, Vossler E, Hull D, et al. (1990) Noncompliance in organ transplant recipients. Transplantation 49: 374-377.

2. Bunzel B, Laederach-Hofmann K (2000) Solid organ transplantation: are there predictors for posttransplant noncompliance? A literature overview. Transplantation 70: 711-716.

3. Weng FL, Israni AK, Joffe MM, Hoy T, Gaughan CA, et al. (2005) Race and electronically measured adherence to immunosuppressive medications after deceased donor renal transplantation. J Am Soc Nephrol 16: 1839-1848.

4. Mayer AD, Dmitrewski J, Squifflet JP, Besse T, Grabensee B, et al. (1997) A report of the European Tacrolimus Multicenter Renal Study Group. Multicenter randomized trial comparing tacrolimus (FK506) and ciclosporin in the prevention of renal allograft rejection. Transplantation 64: 436-443.

5. Pirsch JD, Miller J, Deierhoi MH, Vincenti F, Filo RS (1997) A comparison of tacrolimus (FK506) and cyclosporine for immunosuppression after cadaveric renal transplantation. FK506 Kidney Transplant Study Group. Transplantation 63: 977-983.

6. Vanrenterghem Y, Squifflet JP, Forsythe J, Heeman U, Bäckman L, et al. (1998) Co-administration of tacrolimus and mycophenolate mofetil in cadaveric renal transplant recipients. Transplant Proc 30: 1290-1291.

7. Johnson C, Ahsan N, Gonwa T, Halloran P, Stegall M, et al. (2000) Randomized trial of tacrolimus (Prograf) in combination with azathioprine or mycophenolate mofetil versus cyclosporine (Neoral) with mycophenolate mofetil after cadaveric kidney transplantation. Transplantation 69: 834-841.

8. Ahsan N, Johnson C, Gonwa T, Halloran P, Stegall M, et al. (2001) Randomized trial of tacrolimus plus mycophenolate mofetil or azathioprine versus cyclosporine oral solution (modified) plus mycophenolate mofetil after cadaverc kidney transplantation: results at 2 years. Transplantation 72: 245-250.

9. Nashan B, Moore R, Amlot P, Schmidt AG, Abeywickrama K, et al. (1997) Randomised trial of basiliximab versus placebo for control of acute cellular rejection in renal allograft recipients. CHIB 201 International Study Group. Lancet 350: 1193-1198.

10. Kahan BD, Rajagopalan PR, Hall M (1999) Reduction of the occurrence of acute cellular rejection among renal allograft recipients treated with basiliximab, a chimeric antiinterleukin-2 receptor monoclonal antibody. United States Simulect Renal Study Group. Transplantation 67: 276-284.

11. Vitko S, Klinger M, Salmela K, Wlodarczyk Z, Tyden G, et al. (2005) Two Corticosteroid-Free Regimens-Tacrolimus Monotherapy after Basiliximab Administration e Tacrolimus/Mycophenolate Mofetil-in Comparison with a Standard Triple Regimen in Renal Transplantation: Results of the Atlas Study. Transplantation 80: 1734-1741.

12. Crespo M, Mir M, Marin M, Hurtado S, Estadella C, et al. (2009) De novo kidney transplant recipients need higher doses of Advagraf compared with Prograf to get therapeutic levels. Transplant Proc 41: 2115-2117.

13. Wlodarczyk Z, Squifflet JP, Ostrowski M, Rigotti P, Stefoni S, et al. (2009) Pharmacokinetics for once- versus twice-daily tacrolimus formulations in de novo kidney transplantation: a randomized, open-label trial. Am J Transplant 9: 2505-2513.

14. Barraclough KA, Isbel NM, Johnson DW, Campbell SB, Staatz CE (2011) Once- versus twice-daily tacrolimus: are the formulations truly equivalent? Drugs 71: 1561-1577.

15. Kitada H, Okabe Y, Nishiki T, Miura Y, Kurihara K, et al. (2012) Oneyear follow-up of treatment with once-daily tacrolimus in de novo renal transplant. Exp Clin Transplant 10: 561-567.

16. Yargui L, Chettouh H, Boukni H, Mokhtari N, Berhoune A (2014) Metabolic status of 1088 patients after renal transplantation: assessment 
Citation: La Manna G, Todeschini P, Capelli I, Cappuccilli M, Cuna V, et al. (2014) Advagraf vs. Prograf Immunosuppressive Therapy in De Novo Kidney Transplant: A Single Center Experience. J Transplant Technol Res 4: 129. doi:10.4172/2161-0991.1000129

Page 5 of 5

of twelve years monitoring in Algiers Mustapha Hospital. Saudi J Kidney Dis Transpl 25: 177-184.

17. Ciftci HS, Ayna TK, CalÄ \pm skan YK, Turkmen A, Gurtekin M (2013) Lipid parameters, doses and blood levels of calcineurin inhibitors in renal transplant patients. Indian J Clin Biochem 28: 164-168.

18. Nakamura Y, Hama K, Katayama A, Soga T, Toraishi T, et al. (2012). Safety and efficacy of conversion from twice-daily tacrolimus (Prograf) to once-daily prolonged-release tacrolimus (Graceptor) in stable kidney transplant recipients. Transplant Proc 44: 124-127.
19. Uchida J, Kuwabara N, Machida Y, Iwai T, Naganuma T, et al. (2012) Conversion of stable kidney transplant recipients from twice-daily prograf to a once-daily tacrolimus formulation: a short-term study on its effects on glucose metabolism. Transplant Proc 44: 128-133.

20. Maréchal C, Coche E, Goffin E, Dragean A, Schlieper G, et al. (2012) Progression of coronary artery calcification and thoracic aorta calcification in kidney transplant recipients. Am J Kidney Dis 59: 258-269. 